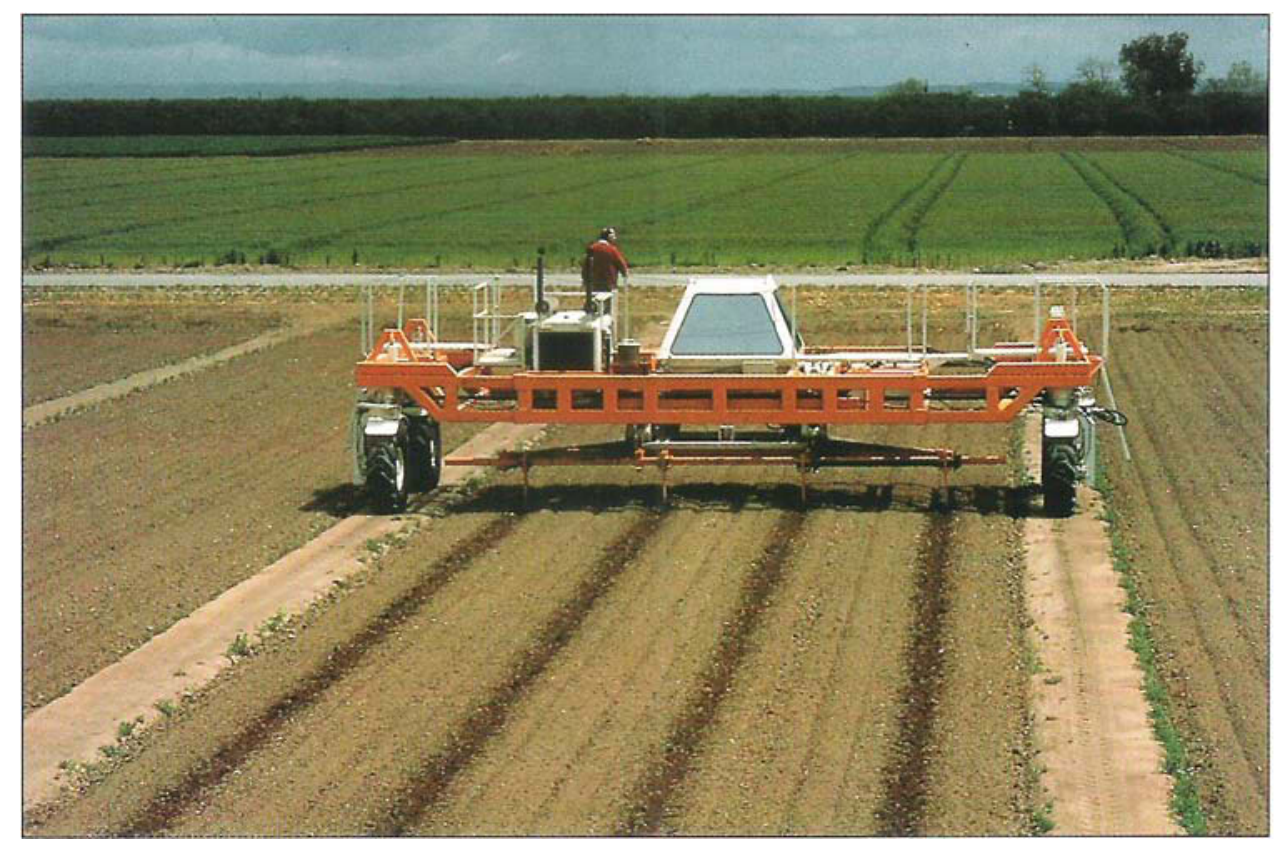

\title{
Deterring compaction of soil by heavy machinery
}

\author{
S. K. Upadhyaya
}

\begin{abstract}
During the last four decades, capital-, chemical-, and energy-intensive agriculture has doubled farm production, while mechanization has reduced agricultural labor by a factor of three. These achievements are not without their problems. For instance, the use of heavy machinery often leads to soil compaction, which in turn is overcome by increasing inputs of energy, chemical fertilizers, and water. All of these practices have a negative bearing on agricultural sustainability.

Farmers can deter soil compaction by resorting to reduced tillage or no tillage, using high-flotation tires or steel or rubber-belted tracks on vehicles, or by using controlled-traffic, wide-span vehicles. Additional research could help pin down the right combination of deterrents.
\end{abstract}

The twofold increase in U.S. agricultural production since 1950 occurred as labor decreased more than threefold (figs. 1 and 2). Increased production coupled with de- creased labor input has resulted in an impressive increase in labor productivity of about $700 \%$. This decrease in labor input has been accomplished by an increase in mechanization. Increase in power input into U.S. agriculture between 1974 and 1987 is shown in figure 3. Notice the rapid increase in power input during the latter part of the 1970s. Although hybrid seeds and increased use of chemical fertilizers and pesticides played a key role in increasing production, mechanization was responsible for decreasing labor input and increasing labor productivity.

Such remarkable progress carried both economic and environmental costs. The economic prosperity of the 1970 s turned into a recession in the first part of the 1980s - a farm crisis that raised questions about the sustainability of the energy-intensive, high-input monoculture of cashcrop production systems.

\section{Problems in U.S. agriculture}

Figure 4 shows the changes in farm income during the 1970s and 1980s. Overproduction, together with increased cost of production and a poor worldwide market for agricultural products, led to a sluggish farm economy in the first part of the 1980s.

During this period of depressed farm economy, many concerns were raised about the sustainability of high off-farm input intensive agriculture. Problems of groundwater pollution due to pesticides, fertilizers, and manures became apparent. Some areas of the country experienced depletion of major aquifers. The soil erosion problem continued to be very serious. Conservation farming area increased from about 25 million acres in 1980 to 100 million acres in 1989. Only about 10 million acres of agricultural land is currently under no-till, strip-till, or ridge-till systems.

At the same time, interest in low-input sustainable agriculture (LISA) has increased nationwide. The objective of LISA is to farm profitably while conserving resources and protecting the environment. Unlike organic farming programs, LISA does not advocate elimination of chemical inputs; instead, it encourages minimum use of off-farm purchased inputs such as synthetic fertilizers, pesticides, and growth stimulants.

Along with increasing concern about the environment has come concern about traffic-induced soil compaction, the result of increased use of large machinery by large farms to accomplish field work in a timely manner. Figure 5 shows the rapid increase in mechanical power and machinery input during the 1970 s, followed by a precipitous drop in the 1980s due to the depressed farm economy. Average farm size has increased (while the number of 


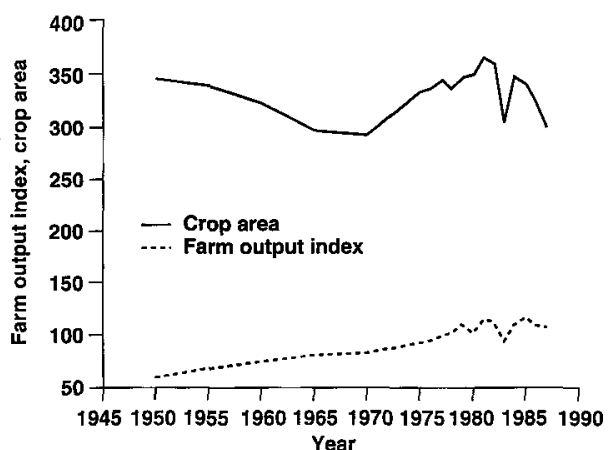

Year

Fig. 1. Changes in agricultural output and area under crop production, 1950-1990. Except for a drop in 1983 resulting from a government program (PIK) to curb overproduction, agricultural output has increased continuously since the 1950s. Crop area has not changed significantly during this time. [Source: Fact Book of Agriculture, 1989]

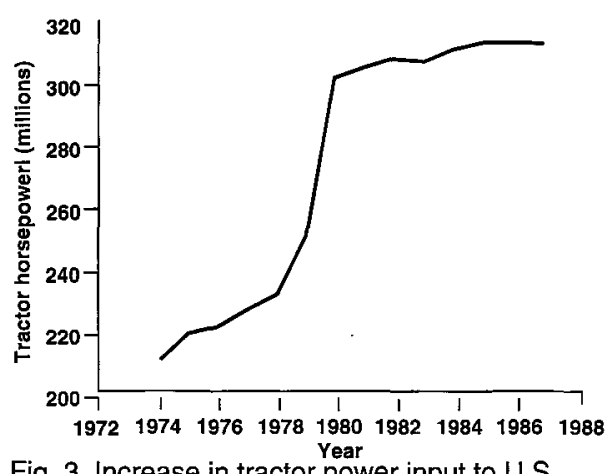

Fig. 3. Increase in tractor power input to U.S. agriculture, 1974-1987. [Source: Agricultural Statistics, 1989]

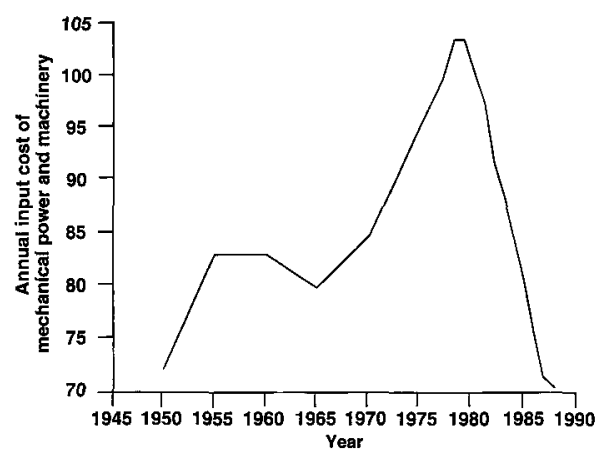

Fig. 5. Annual input cost of mechanical power and machinery, 1950-1986. [Source: Fact Book of Agriculture, 1989]

farms has declined) over the past 15 years (fig. 6), and average tractor size has more than doubled in three decades. Modern four-wheel-drive tractors weigh about 15 tons. Use of such heavy machinery can lead to excessive soil compaction in some soils.

\section{Soil compaction}

Traffic-induced soil compaction leads to the collapse of soil pore space, which in turn leads to reduced infiltration and increased runoff, resulting in soil erosion. Moreover, compacted soil remains colder

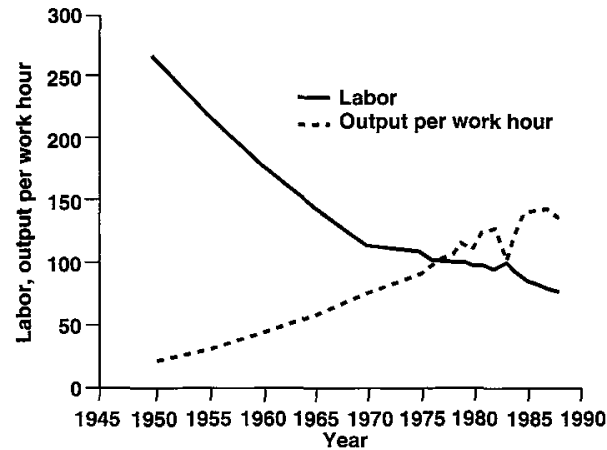

Fig. 2. Changes in labor hours and per-hour productivity, 1950-1990. [Source: Fact Book of Agriculture, 1989]

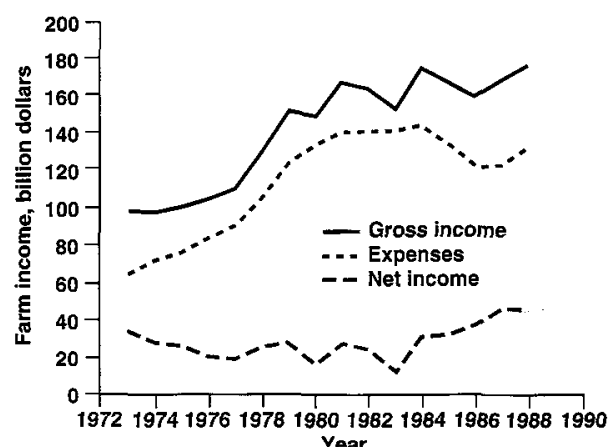

Fig. 4. Changes in gross income, expenditures, and net income on a current dollar basis, 19731988. [Source: Agricultural Statistics, 1989]

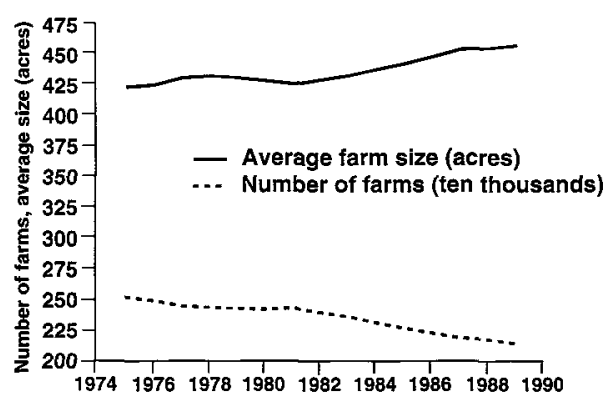

Fig. 6. Decreases in number and increases in size of the average U.S. farm, 1976-1989. [Source: Implement and Tractor, 1974-1989]

longer, and thereby delays planting and germination. The resulting loss of soil oxygen (anaerobic condition) may lead to loss of nitrogen. Soil compaction may also reduce microbial activity, hinder plant root development, and decrease yields, particularly of root crops. This yield reduction may not always be noticeable. The effects of soil compaction can often be offset by increased use of water and fertilizer. However, these increases in water and fertilization negate the intent of agricultural sustainability.

Subsoiling is often used to alleviate soil compaction. However, if heavy machinery is used after subsoiling, soil compaction may worsen. It is not unusual to see even bigger tractors called in to subsoil the same soil after several years of deep tilling. In 1990, James H. Taylor stated in a paper on soil compaction that, even when practiced in a properly designed cultural system, subsoiling is treating the symptom and intensifying the disease. It is apparent that preventing soil compaction at the outset, rather than attempting to reclaim compacted soil, should take precedence. Soil compaction should be managed to provide optimum mobility and timely movement of machinery through the field. Moreover, such management should provide an optimum environment for plant growth and optimum conservation of soil and water.

\section{Controlling soil compaction}

Minimum- and no-tillage systems reduce traffic in fields and thereby reduce soil compaction and improve the timeliness of field operations. The elimination of primary tillage operations that require high draft (pulling force) helps conserve energy and also reduces soil compaction by preventing the need for heavier tractors. To reduce surface soil compaction, heavy tractors are often equipped with large flotation tires. Vehicles equipped with steel or rubber tracks reduce ground pressure about 5.5 pounds per square inch (psi) versus pressure approximately equal to inflation pressure plus 2 to 3 psi, corresponding to carcass stiffness in wheeled vehicles. Such systems often produce less surface compaction.

An ultralow-pressure (6 to 9 psi), multiple-tire system (for instance, six tires per axle) with tires loaded to rated deflection (that recommended by tire manufacturer) shows promise in enhancing traction while reducing soil compaction. Controlled traffic, wide-span, or Gantry-type vehicles are under investigation at the $\mathrm{Na}$ tional Soil Dynamics Laboratory, USDA Agricultural Research Service in Shafter, California, and at the University of Georgia, Texas A\&M University (studying the cable Gantry system), and Clemson University (studying a modified tobacco harvester) to determine their applicability in reducing soil compaction and in evaluating the economic feasibility of controlledtraffic production systems.

S. K. Upadhyaya is Associate Professor, Department of Agricultural Engineering, UC Davis.

For more information, see "Implications of Use of Large Tractors on Agricultural Sustainability" by S. K. Upadhyaya, published in the 1990 Proceedings of the International Symposium on Tractors in Tokachi, pp. 25-44. 